\title{
Experimental Organism Malignant Sarcoma Arising From Fibroadenoma
}

National Cancer Institute

\section{Source}

National Cancer Institute. Experimental Organism Malignant Sarcoma Arising From

Fibroadenoma. NCI Thesaurus. Code C124613.

A malignant mesenchymal neoplasm that arises from a pre-existing benign fibroadenoma. 